\title{
Optimizing the Surface Quality of Textile Composites for Bonded Repairs
}

\section{Riddhi Naik 1, Sunil Joshi 2}

Department of Mechanical and Aerospace Engineering, Nanyang Technological University, Singapore.

1 Affiliation 1; riddhidh001@e.ntu.edu.sg

2 Affiliation 2; mscjoshi@ntu.edu.sg

\section{ABSTRACT}

With the accelerated use of woven composites in many industries like aerospace, marine, sports, construction, automobile ${ }^{*}$ Correspondence to Author: and many more their repairs have become an inevitable part of Sunil Joshi.

it. The current problem with repairs is, even with precise machinDepartment of Mechanical and ing there are bond failures due to inadequate surface quality. In this research, machining techniques like stepped and scarf repairs and abrasion techniques are used on the woven coupons to evaluate their influence on the surface characteristics. Preliminary evaluation of the surface characteristics is done using a surface profiler, to measure the topographical features like surface roughness and amplitude of the peaks and valleys. Further, the results obtained from the profiler are validated using microscopy and contact angle test to identify the trend between surface roughness and wettability. Finally, the results obtained from the various experiments helps us to identify an optimum surface quality needed prior to bonding in terms of surface roughness Aerospace Engineering, Nanyang Technological University, Singapore.

Email: mscjoshi@ntu.edu.sg and contact angle. The results for $3 \mathrm{~K}$ woven glass fibre shows an optimum surface roughness in the range of $2-4 \mu \mathrm{m}$ and contact angle below $60^{\circ}$

How to cite this article:

Riddhi Naik and Sunil Joshi, Optimizing the Surface Quality of Textile Composites for Bonded Repairs. International Research Journal of Materials Sciences and Applications, 2017; $1: 7$.

\section{eSciencePublisher。}

$$
\text { eSciPub LLC, Houston, TX USA. }
$$

Keywords: Surface modification; Surface quality, Microscopy, Website: http://escipub.com/ Surface roughness $\mathrm{Ra}$ and Arithmetic mean roughness $\mathrm{Rz}$ 


\section{Introduction}

Currently, fibre reinforced composites are becoming increasingly important in various fields like aviation, automation, shipping, medical, oil and gas and many other industries. Increased use of fibre reinforced composites with low cost, non-woven class of fibre possess limitations in mechanical properties. Woven composites with their excellent stiffness, strength and toughness properties have received greater attention in recent times. The major benefits of using woven fibres is improved microstructural properties due to their discrete fibre arrangement.

Woven composites have been widely used in commercial airplane structures $[1,2]$. The application of woven composite in aviation increases the importance of repair methodology for these types of composites. In general, composites have been repaired using scarf bond repair technique. Scarf bond technique was investigated in 1980 by Jones [3] to evaluate its mechanical performance. Following the success of the investigation, considerable research was done both experimentally and numerically on scarf repair. Wang [4] did a thorough study on structural parameters of bonded repairs to come with strain based design methodology for scarf repair. Lin [5] simulated a model using threedimensional progressive analysis to predict the strength of a scarf repaired structure.
There is a lot of research [6-10] being done on new repair patch, its compatibility with the parent material, the modes of bond failures in composite repairs and automated machining of the scarf. Despite of this there is a lack of research focusing on scarf repairs for woven composites. Most research [11-14] on woven composites focuses on macro-scale mechanical properties or the overall bond strength. In addition to the mechanical properties, the machining defects and surface quality are quite dissimilar comparing to non-woven composites. These surface quality and machining defect parameters directly influence bond quality. Therefore, it is necessary to investigate the surface quality and machining defects caused during scarf and stepped lap repair technique on woven composites.

The two important stages of bonded composite repairs can be summarised as scraping out the damaged part and bonding of the new incoming repair patch. However, in-between these two steps there is an important stage which needs to be focused to get the whole repair more reliable and robust; surface quality, as shown in Figure 1. A good surface quality prior to bonding will be a very beneficial step in avoiding the premature failure and minimize the overall cost and downtime of the aircraft. Moreover, it will also increase the reliability of bonded repairs instead of confining it to thin structures and small cosmetic repairs.

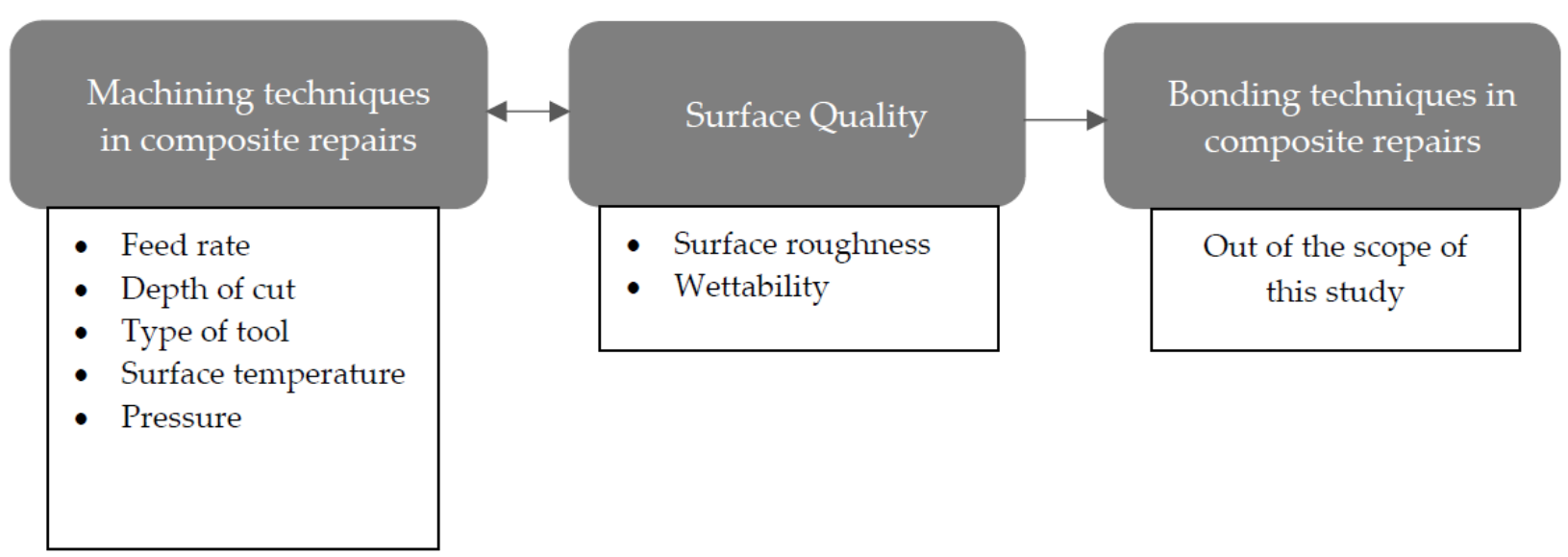

\section{Figure 1: Three important criteria in composite repair}

In this paper, 3K woven glass fibre prepreg are Scarf and stepped repair are performed on the made into several coupons as research subjects. coupons and experiments are conducted to 
evaluate the surface finish parameters in terms of surface roughness and wettability with respect to machining parameters during repair. Further analysis is carried out on microscope to understand the prepreg laminate's post machining characteristics.

\section{Materials and Methods}

\subsection{Material preparation}

Woven glass fibre Prepreg of $600 \mathrm{gsm}$ is used for this experiment as shown in Figure 2. The material consists of Tencate E722 mid temperature curing modified epoxy component.
Plies of size $200 \times 200 \mathrm{~mm}$ were cut to make a panel with a layup sequence of $[ \pm 45,0 / 90, \pm 45$, $0 / 90] \mathrm{S}$. The test coupons were prepared using vacuum bagging under an industrial oven with a ramp rate of $3^{\circ} \mathrm{C} / \mathrm{min}$.

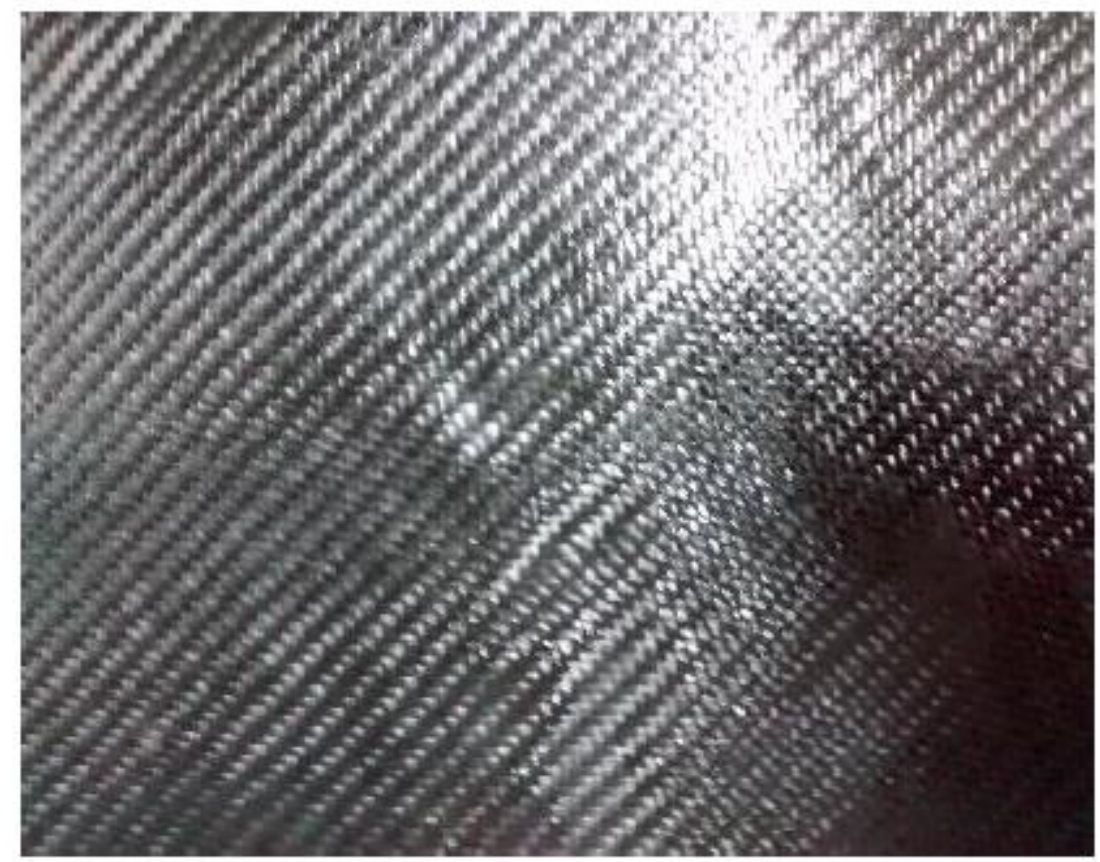

Figure 2: $600 \mathrm{gsm}$ woven glass fibre

\subsection{GFRP coupon test}

Table 1: Different types of test carried out with GFRP coupons

\begin{tabular}{lll}
\hline \multicolumn{2}{l}{ GFRP Coupon test } & \\
\hline Name & Repair Technique & Tool used \\
Type 1 & Stepped & Power sander \\
Type 2 & Scarfed & Power sanded and abraded with P80 grit sand paper \\
Type 2 & Scarfed & Power sanded and abraded with P220 grit sand paper \\
Type 2 & Scarfed & Power sanded and abraded with P400 grit sand paper \\
Type 3 & Stepped & Router with a double cut milling bit \\
\hline
\end{tabular}

Table 1, gives a detailed description of three different types of coupon tests to check the effects of machining on the surface quality of stepped and scarfed repairs. Figure 3, shows the test setup and Figure 4 shows the schematic of different tool paths for machining. 


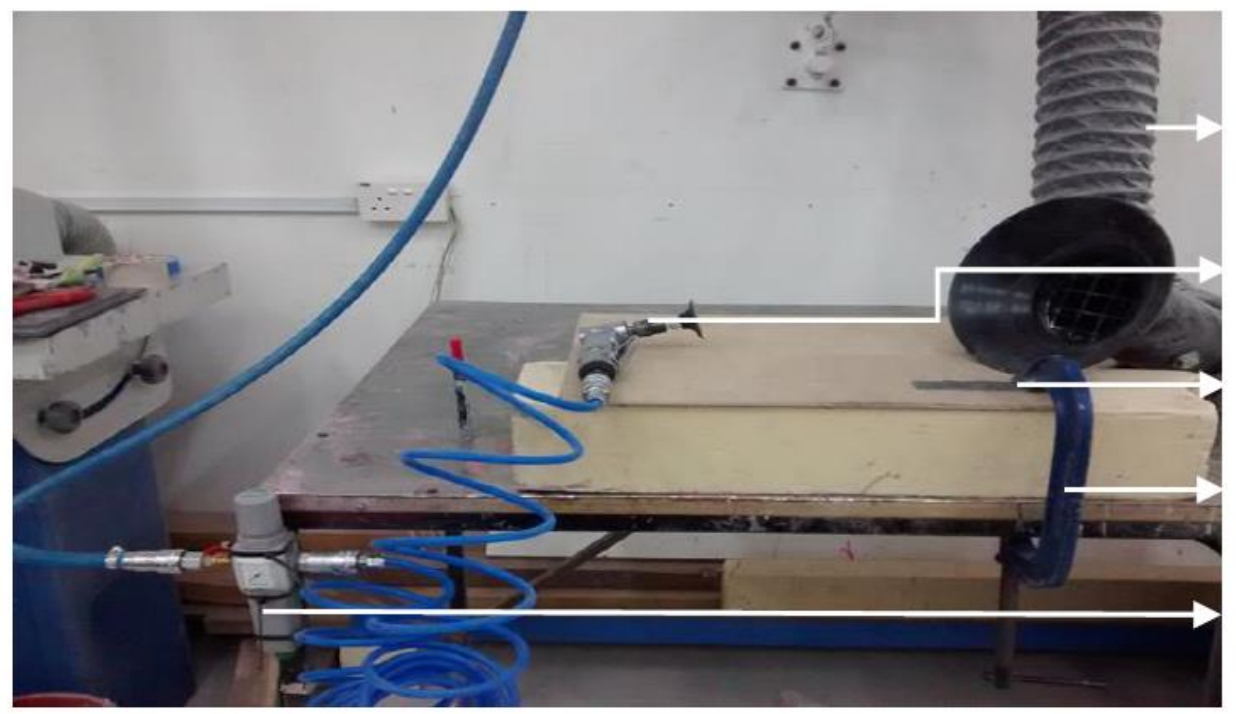

Vacuum hose for

dust extraction

Power sander

Coupon

Clamp

Pressure gauge

Figure 3: Experimental setup for coupon test

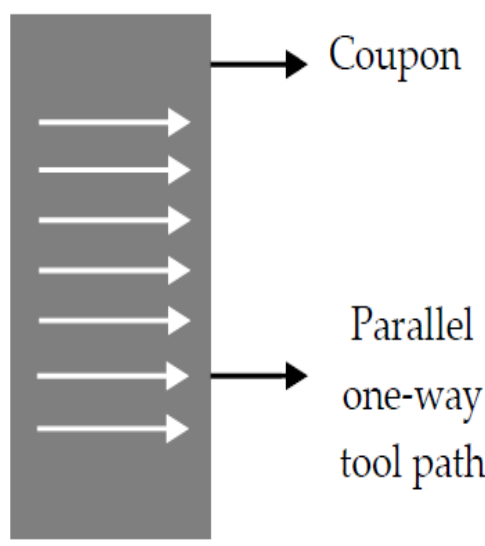

Type 1

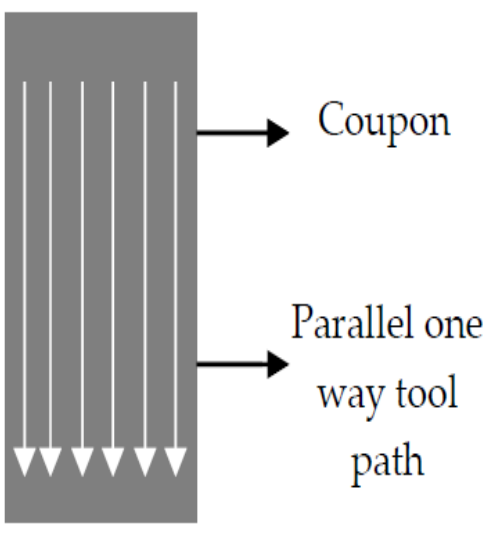

Type 2

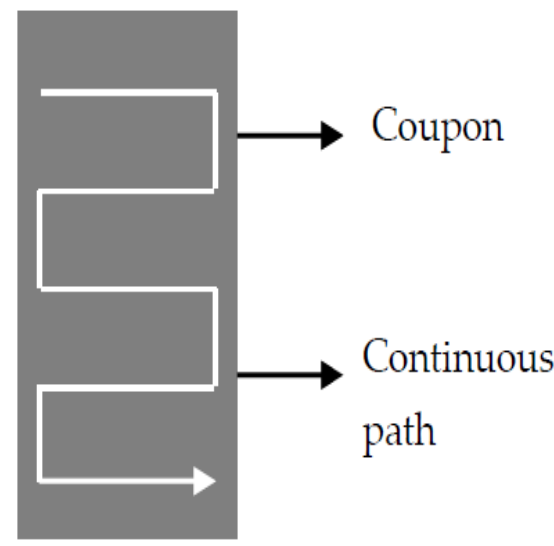

Type 3

\section{Figure 4: Schematic diagrams for all three types of machining}

\subsection{Procedures for making scarf and step repairs on coupon}

The coupon is cleaned with acetone to ensure no contaminants are present and weigh the panel/coupon before starting the operation. The damage area along with the desired dimension to be removed through machining (i.e. length, depth and breadth of each step, in case of step sanding) and (scarf angle and the scarf length in case of tapered scarf) are marked. A pressure regulator is fitted for the tool to control the RPM of the tool. The temperature and mass changes before and after machining are measured using a thermal imager and weighing machine.

\subsection{Surface profile}

After initial visual inspection of the coupons from machining, it is important to quantify the surface characteristics. This is done by using a Taylor Hobson surface profiler configured with Talyscan 150 software. During the experiment a $2 \mathrm{D}$ profile is chosen and the stylus runs over a certain sampling length i.e. the breadth of the coupon to record all the x-spacing and $z$ amplitude coordinates as shown in Figure 5. A total of 2401 points are obtained from the stylus and using the values of $x$ and $z$ coordinates all the surface profile parameters such as $\mathrm{Ra}, \mathrm{Rz}$, $\mathrm{Rt}, \mathrm{Rq}$ are calculated which are discussed in depth in the results section. 
b

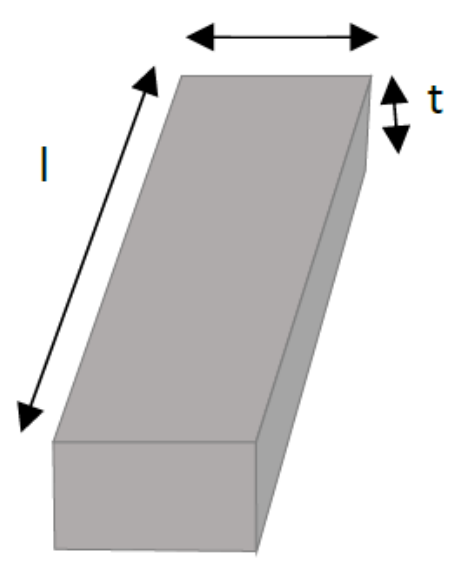

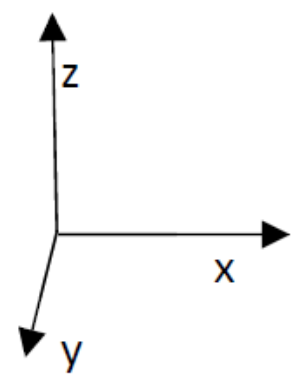

Figure 5: Schematic for coupon dimensions

\subsection{Microscopy}

The coupons from each type are observed under a carl-zeiss Axioskop microscope and important features like bruising marks, coarse grit of grains etc. are studied.

\subsection{Contact angle measurement}

A micro syringe was used to drop $5 \mu$ of distilled water on the coupon and allowed to stay for 60 seconds. Distilled water at $20^{\circ} \mathrm{C}$ is used to avoid contamination and the coupons are dried properly to avoid moisture absorption. An angle of $\theta=41.20^{\circ}$ was obtained from the measurement using a camera. The images were post processed in MATLAB to measure the contact angle. The contact angle ranges from $0^{\circ}$ to $180^{\circ}$ where $0^{\circ}$ indicates perfect wetting. Smaller the contact angle higher is the surface energy. This ensures good bonding characteristics. Figure 6, shows the liquid drop on a substrate to measure contact angle.

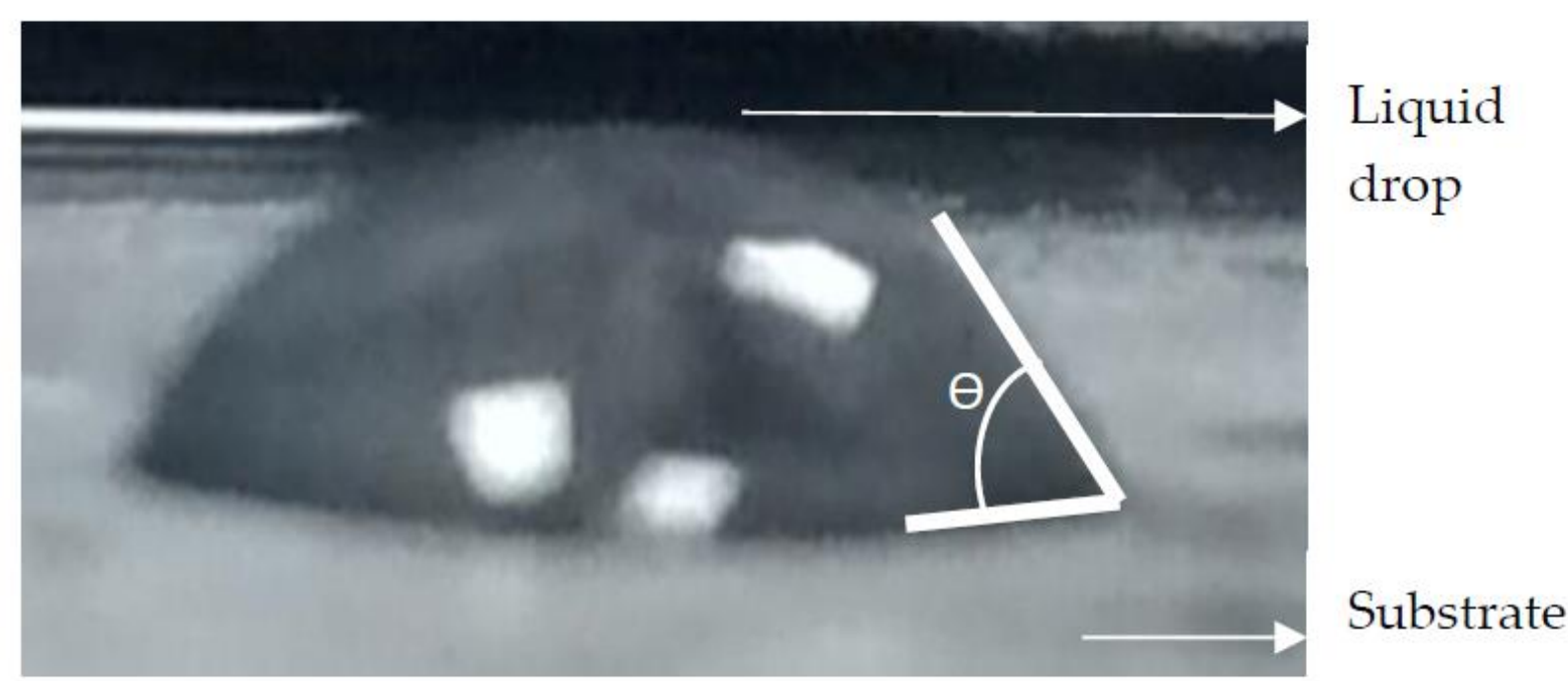

Figure 6: Contact angle measurement

\section{Results}

A total of 20 coupons were tested, four from each type and subtype. The surface roughness parameters obtained were justified and supported with further microscopic examination. At the end a contact angle analysis was done to predict the bonding characteristics. 


\subsection{Types of coupon test}

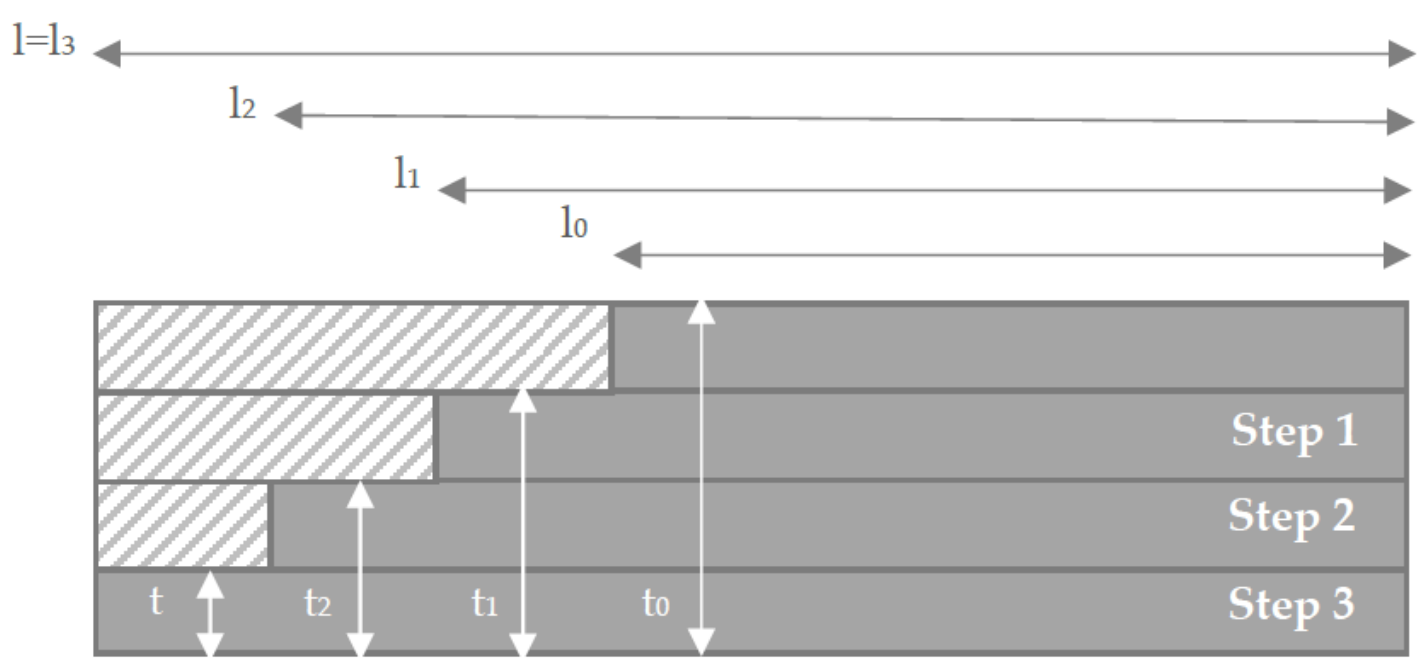

\section{Figure 7: Schematic of type 1 coupon test}

All the tests for type 1 (see Figure 7) were conducted at 3 bar pressure using a power sander running at 20,000 RPM attached with a P120 grit aluminium oxide sanding disc. The material removal was carried out as shown in the schematics where the hatched part denotes the removed material. The formulas listed below were used to find the material removal rate.
Total volume removed $=\sum(t n-1-t n) \quad \times b$ $\times(l-\ln -1) n=3 n=1$ (1)

Material removal rate $=$ (Total volume removed $) /($ Total time taken ) (2)

Volume removed $=12 \times\left(l-l^{\prime}\right) \times h \times b(3)$

Total volume removed $=\sum(t n-1-t n) \times b$ $\times(l-\ln -1) n=8 n=1$ (4)

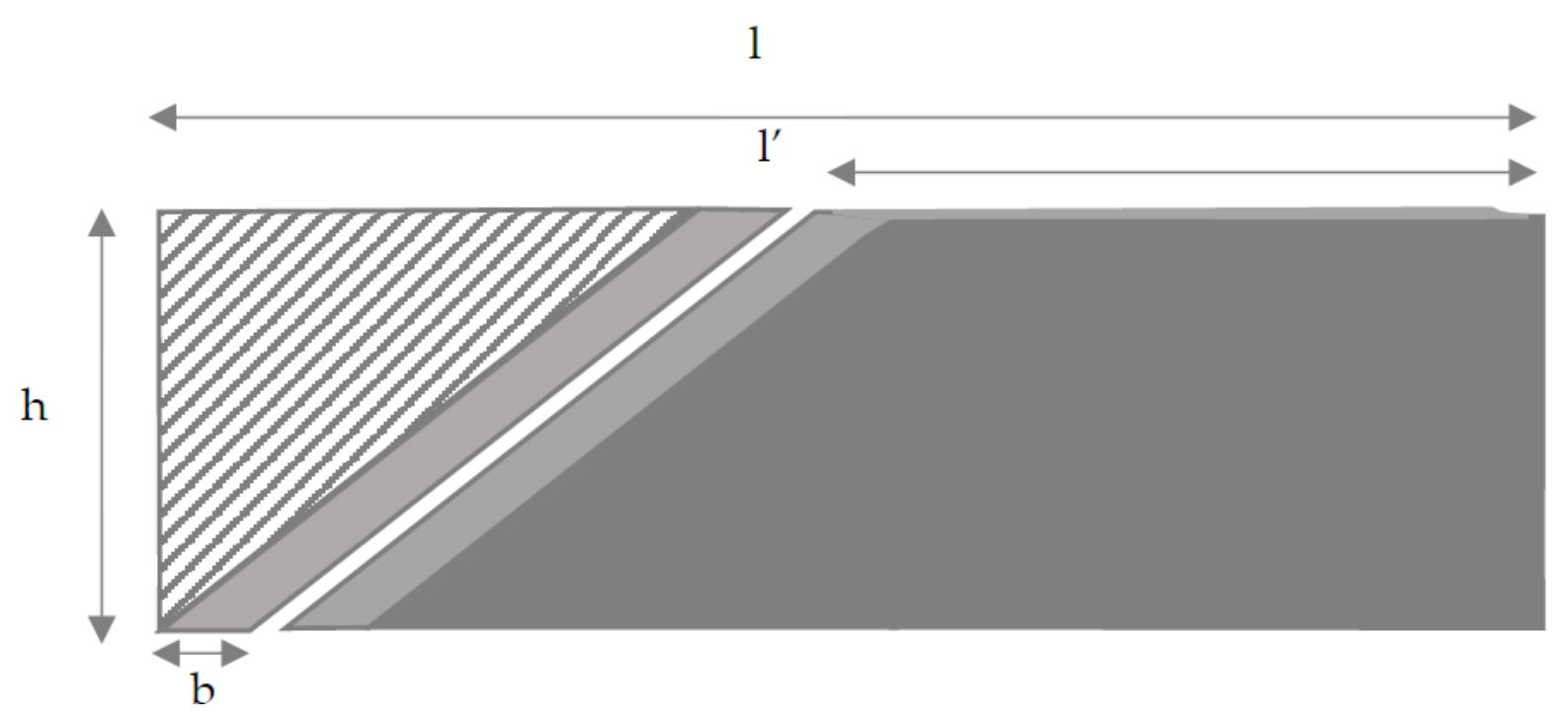

Figure 8: Schematic of Type 2 coupon test

In type 3 test, a milling router was used with double cut milling bit. Layer by layer removal was adopted (see Figure 9) and precise machining was done to find out the effects of milling on surface quality of woven glass fibre prepreg. 
1

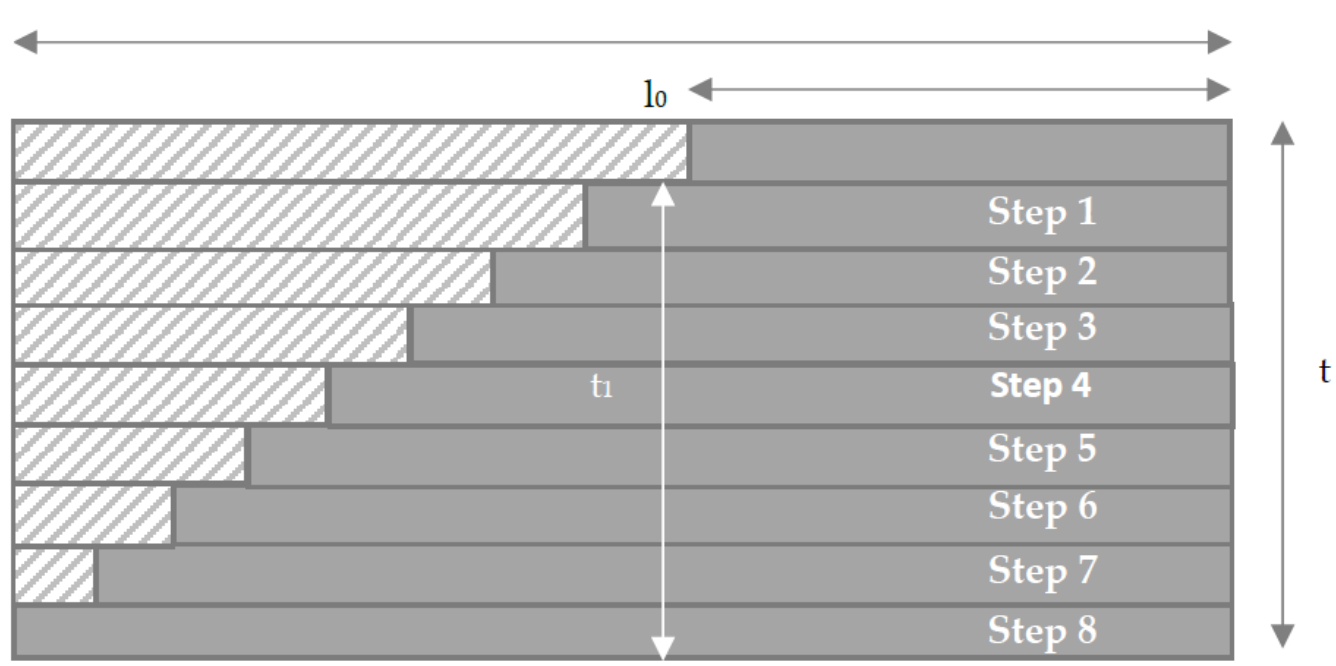

Figure 9: Schematic of type 3 coupon test

\subsection{Surface profile of coupon test}

The surface profiles shown below were obtained using a Taylor Hobson surface profiler where a total of 2410 points were obtained. The profiles were then levelled up with respect to a datum and the corresponding roughness values were calculated. A total of 6 readings were taken on each coupon along the width of each step. The scans 1, 2 and 3 in Figure 10, shows readings for steps 1,2 and 3 respectively as shown in Figure 7. In case of type 2, three scans on the taper were taken as shown in Figure 11,12,13 and for type 3, scans 1, 2, 3 and 4 in Figure 14 shows the readings on the respective steps 1,3 , 5 and 7 from Figure 9.

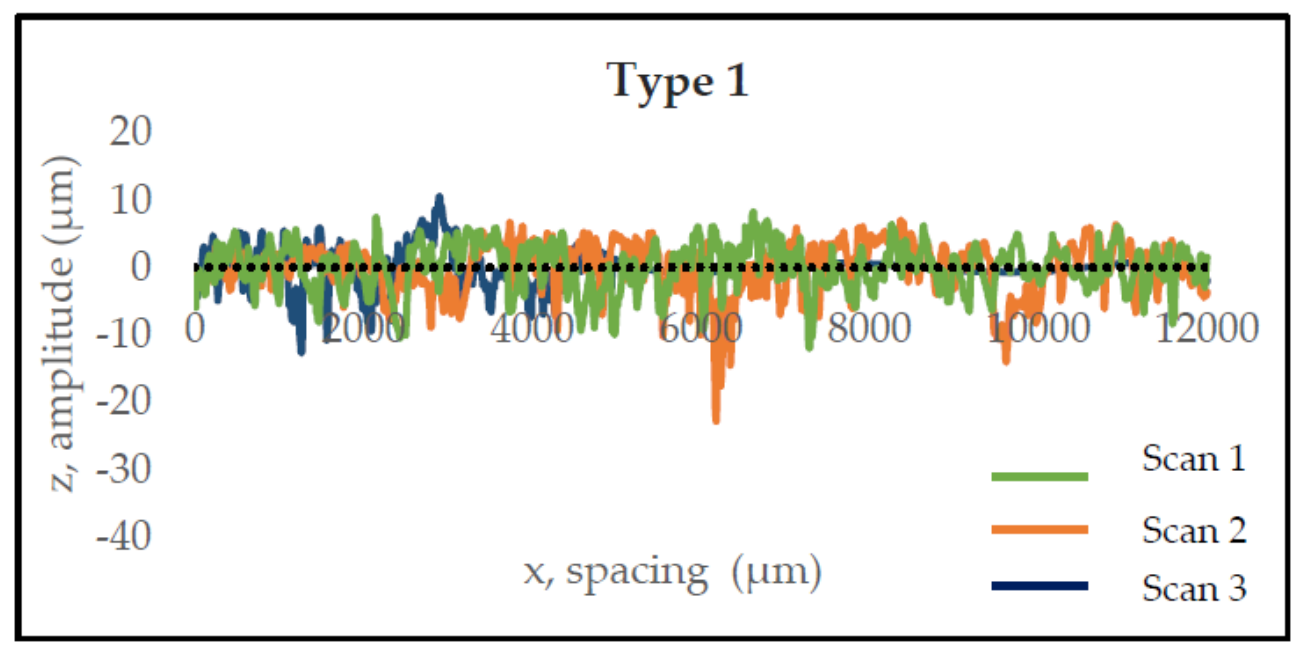

Figure 10: Surface profile graph for type 1 coupon test 


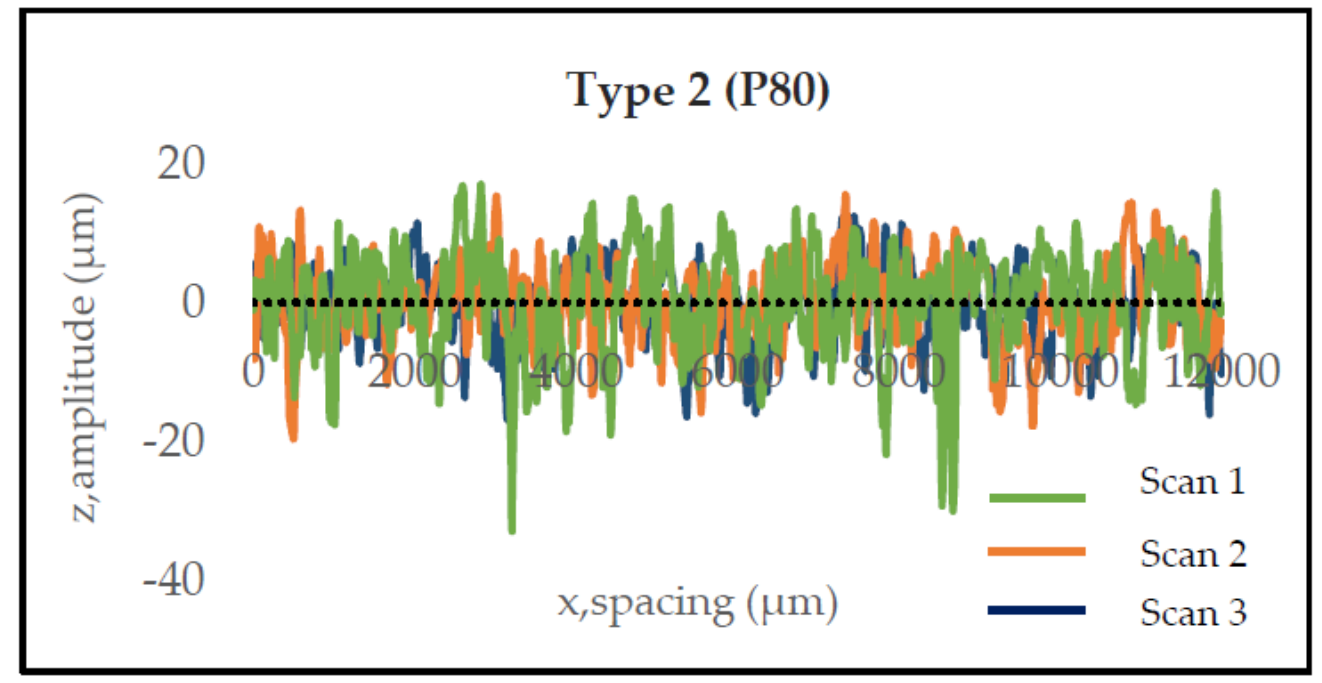

Figure 11: Surface profile graph for type 2 coupon test, abraded with P80 grit

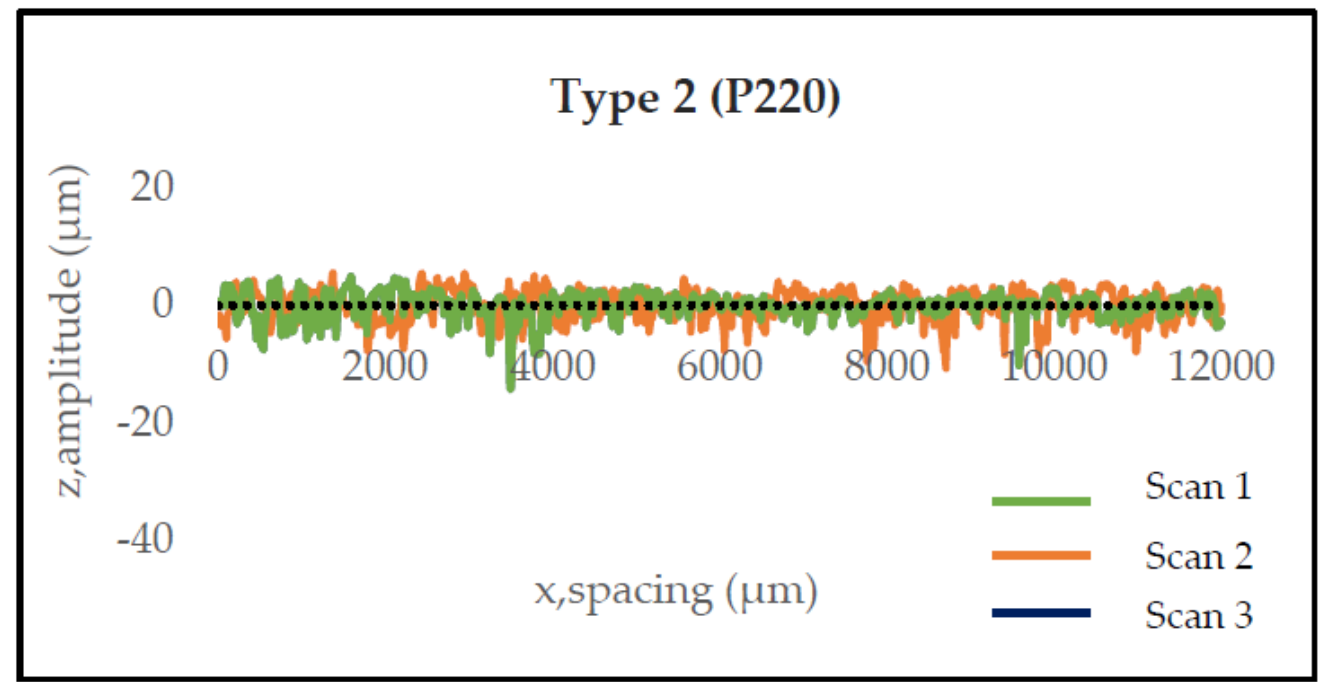

Figure 12: Surface profile graph for type 2 coupon test, abraded with P220 grit

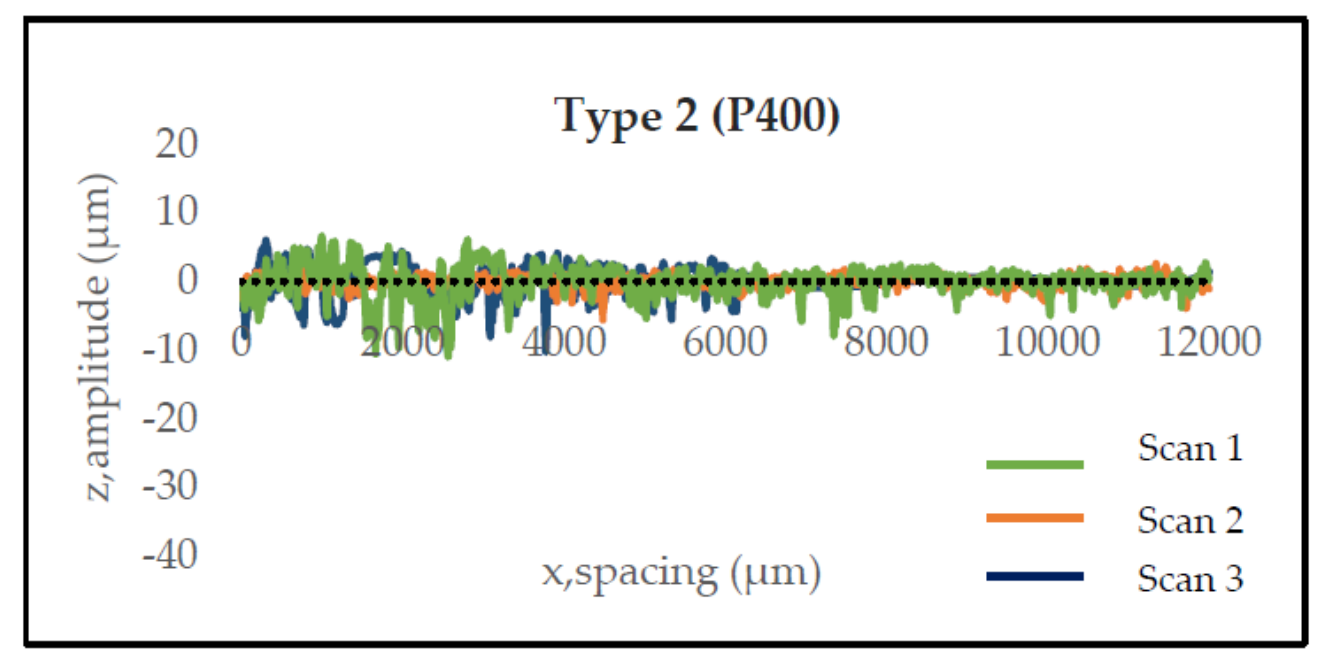

Figure 13: Surface profile graph for type 2 coupon test, abraded with P400 grit 


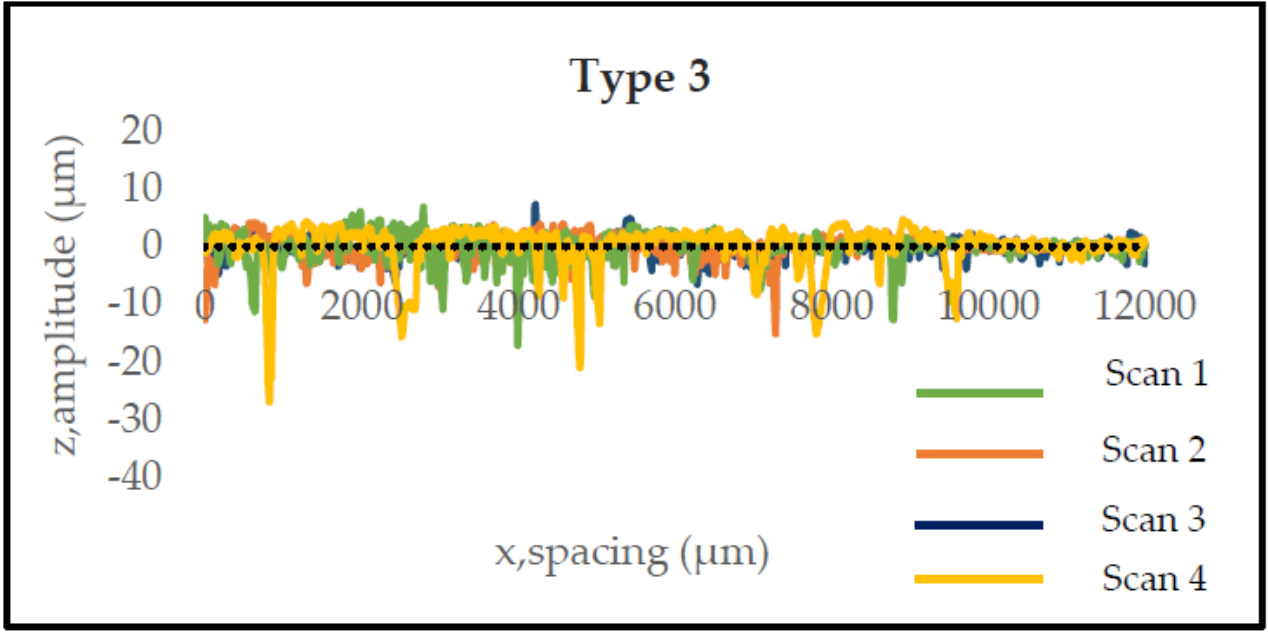

Figure 14: Surface profile graph for type 3 coupon test

In case of type 1, No abrasion technique was used after sanding which is evident from the fewer peaks and valleys on the surface as shown in Figure 10. However, in case of type 2 the profile of the surface abraded with $\mathrm{P} 80$ grit sand paper has the highest peaks and valleys (see Figure 11) with P 400 marking the lowest ((see Figure 13). In type 2, coupon sanded with P220 grit (see Figure 12) a moderate surface roughness was obtained whereas, in type 3 due to the use of double cut milling bit, the peaks and valleys are sharp as shown in Figure 14, resulting in increased roughness values. The values obtained from all the points were averaged to calculate roughness parameters.

\subsection{Roughness values}

\section{Table 2: Surface topology characteristics}

\begin{tabular}{ccc}
\hline Parameters & $\operatorname{Ra}(\mu \mathrm{m})$ & $\mathrm{Rz}(\mu \mathrm{m})$ \\
\hline Type 1 & 2.51 & 11.28 \\
Type 2 (P80) & 4.78 & 17.89 \\
Type 2 (P220) & 2.44 & 12.31 \\
Type 2 (P400) & 1.01 & 5.39 \\
Type 3 & 3.87 & 22.52 \\
\hline
\end{tabular}

Table 2, shows the respective values of different types of coupon tests. Ra is obtained as the average roughness of all the values obtained from the $x$ and $z$ coordinates, however being the average roughness there can be some
Roughness parameters like $\mathrm{Ra}, \mathrm{Rq}$ and $\mathrm{Rz}$ were calculated from the values obtained from respective $x$ and $z$ coordinates of surface profile graphs.

$\mathrm{Ra}=$ Average roughness

$\boldsymbol{R} \boldsymbol{a}=1 n \sum|y i-\bar{y}| n i=1$ (5)

$R q=$ the root mean square of surface roughness $\boldsymbol{R} \boldsymbol{q}=\sqrt{ } 1 n \sum r n 2 n i=1(6)$

$R z=$ the mean roughness is one of the accurate parameters to quantify the surface

$\boldsymbol{R} \boldsymbol{z}=(Y p 1+Y p 2+Y p 3+Y p 4+Y p 5+Y p 6+Y p 7+Y p 8+Y$ $p 9+Y p 10)+(Y v 1+Y v 2+Y v 3+Y v 4+Y v 5+Y v 6+Y v 7$ $+Y v 8+Y v 9+Y v 10) 10(7)$ 
values because it doesn't give a clear indication. Nevertheless, from the values of $\mathrm{Rz}$ it can be clearly seen that $\mathrm{P} 400$ has very low value of 5.39 $\mu \mathrm{m}$. Along with this the coarse grit of P80 and milling (type 3 ) points the roughness values as high as $4.78 \mu \mathrm{m}$ and $3.87 \mu \mathrm{m}$ respectively. Surface roughness and amplitude serves as the initial parameter to analyse the surface quality and the basis for further validation.

\subsection{Microscopic examination}

After the coupons are tested under the surface profiler, it is necessary to observe the micro nonuniformities on the coupon surface caused during machining. The coupons from each type were observed under a carl-ziess Axioskop microscope. The microscope is connected to a computer which gives the image of area

observed under the microscope. Looking at the surface profile of each coupon, the abnormal changes in its peaks and valleys are marked. These marked regions are then analysed under the microscope with different lenses starting from $5 x$ to $20 x$ to relate those changes with the microscopic images.

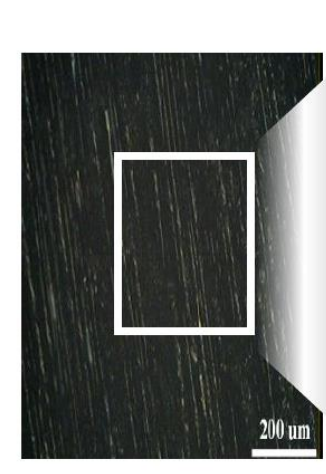

$5.0 \mathrm{X}$

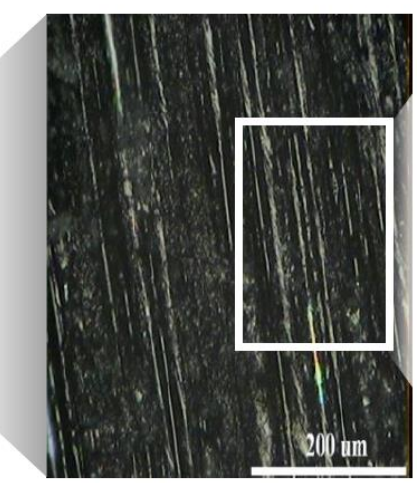

$10.0 \mathrm{X}$

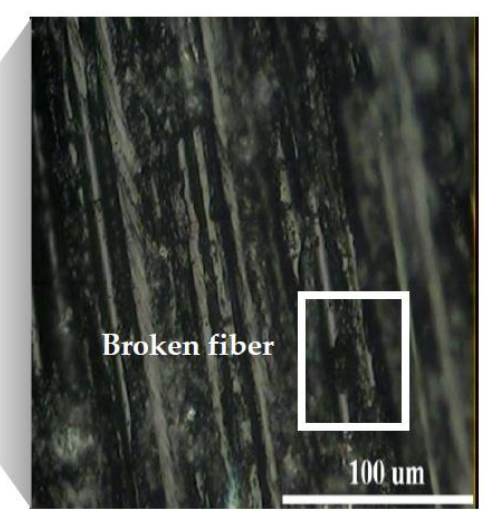

$20.0 X$

Figure 15: Microscopic inspection in type 1 test

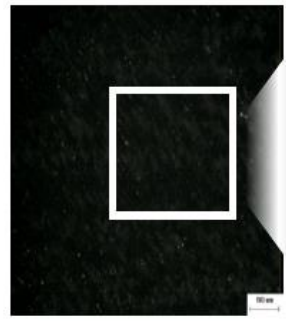

$5.0 X$

$10.0 \times$

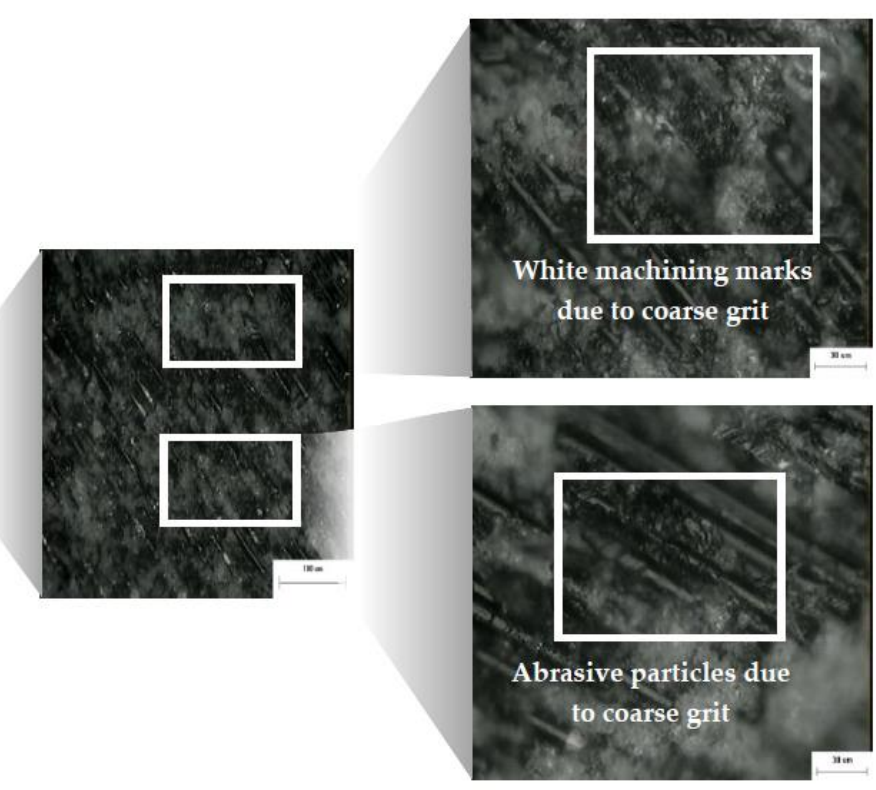

$20.0 \times$ 


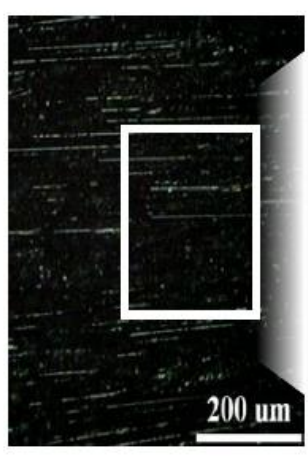

$5.0 \times$

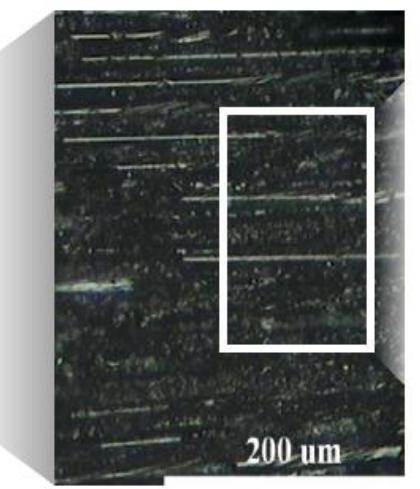

$10.0 \times$

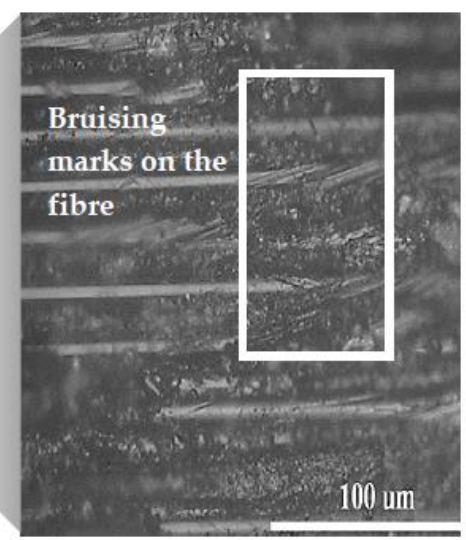

$20.0 X$

Figure 17: Microscopic inspection in type 2, P220 grit test

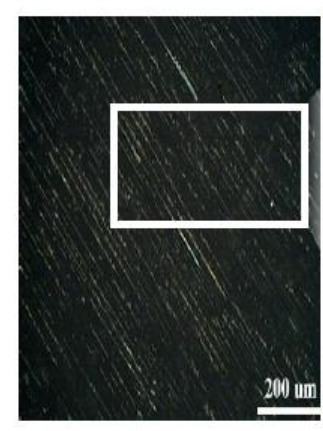

$5.0 X$

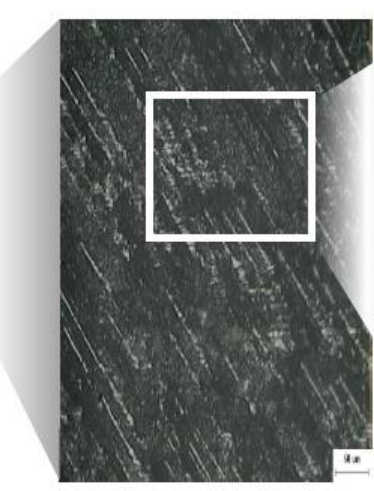

$10.0 X$

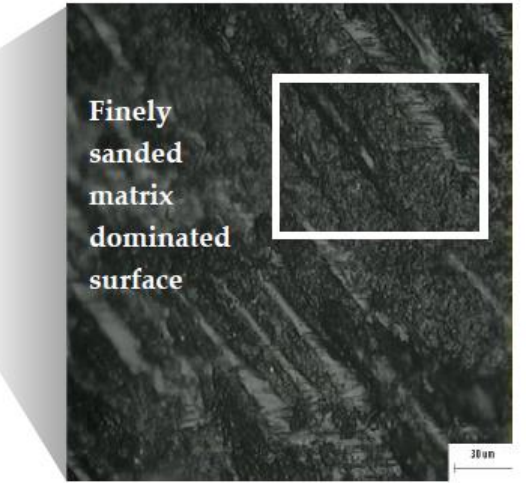

$20.0 X$

Figure 18: Microscopic inspection in type 2, P400 grit test
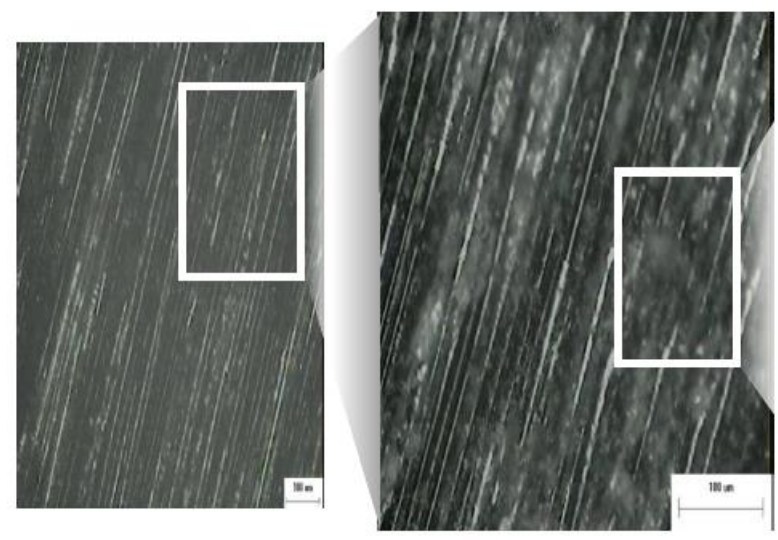

$10.0 X$

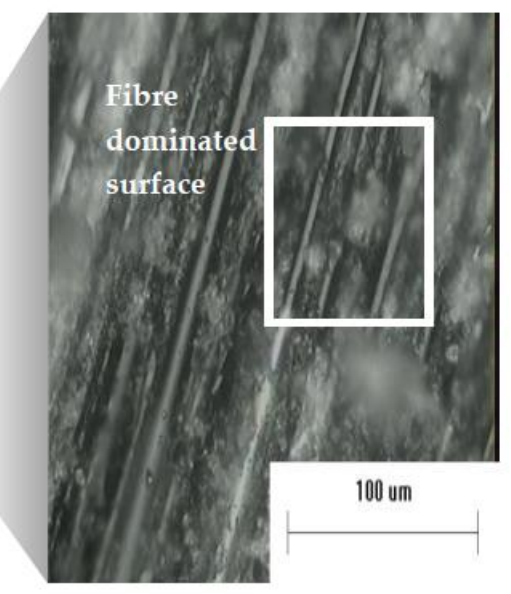

$20.0 X$

Figure 19: Microscopic inspection in type 3 test

The coupons observed under $5 x$ shows the high power lens of $10 x$ and $20 x$ to get a more unusual behaviour which is then focussed under detailed understanding. In the 20x zoomed-in 
image, a broken fibre can be seen in Figure 15, however the phenomenon is rare and it was observed only in one spot in the entire coupon. This was certainly different in case of Figure 16 where white abrasive marks are seen due to the abrasion with coarse grit sand paper which in turn results in a very high roughness value. Along with this the coarse particles can also be noticed on the surface of the fibre. A matrix dominated surface is obtained with P400 as shown in Figure 18 due to fine sanding whereas a fibre dominated surface is obtained due to the precise machining (see Figure 19). A fibre dominated surface can serve well for the incoming new patch and provide more reliable bonds.

\section{Discussions}

The enhancement of bonding quality of the woven glass fibre is improved by both physical and chemical modification. The physical modification is done by sanding or grit blasting on the surface using different grits of sand paper or other tools. Sanding the fibres results in enlarging the micro level contact area for better mechanical interlocking. The physical modification is measured using surface roughness from surface profiler. The chemical modification is measured from the surface energy measured using contact angle. Reducing the contact angle increases the wettability between the parent material and the adhesive ensuring better bonding characteristics.

\subsection{Key parameters affecting the surface quality are:}

\subsubsection{Tool path}

The three types of tests were conducted using different tool paths i.e. parallel one way and continuous tool path as described in the earlier section. The parallel one-way tool path produced the best surface finish due to the consistent movement to cut the fibres. The machining time of this tool path was long in cycles to complete the process. The zigzag tool path took shorter cycles but resulted in uneven surface

finish and high temperature change. The high temperature could result in tool wear. The continuous tool path allowed tight contact with the part allowing the tool to cut precise contours. Continuous path tool way is beneficial in case of curved parts where the spacing is a function of the cutting depth.

\subsubsection{Cutting depth}

The depth of cut varied in both the type 1 and type 3 experiments. One major noticeable trend from most of the coupons was the surface roughness value that increased from first step to last. This change is possible due to the residual temperature from machining the previous steps. Although, the thickness of each step was planned to cut ply-by-ply but due to machining inaccuracy, in some of the coupons the thickness of steps varied slightly. The fluctuations with this trend is due to increased surface roughness due to inadequate removal of fibres and resin. Thus, the influence of cutting depth cannot be a direct function of surface quality.

\subsubsection{Machining techniques for material removal}

When the tool slide against the surface, frictional forces are generated and the temperature increases. The debris produced by grinding and milling may coalescence at high temperature making the surface rough. During milling the removal of fibre from the matrix is partial which leads to high surface roughness. Machining of thermosets at high speeds heat inside the material is dispersed inside the matrix and results in rough surface appearance. This is the reason that cutting speed, tool geometry and other machining parameters have a significant effect on the surface roughness of epoxy based composites. Internal residual stresses released after machining also leads to deformation and change in surface texture. It can be said from the microscopic analysis, the fibres fracture by cutting do not result in poor surface quality but a debonding at the fibre/matrix interfaces creates more damage to the surface.

\subsubsection{Sanding techniques}

Apart from the type of material of the sandpaper the abrasive size also affects the surface profile 
of the specimen. With the coarser grit of paper, the roughness peaks are pointed because of the sharp and uneven abrasive particles. The coarse grid of P80 hand sanding resulted in a high average surface roughness. Increase in grit size resulted in smoother surface with low average surface roughness. Milling without sanding resulted in average surface roughness value of $3.87 \mu \mathrm{m}$. Relying only on the Ra value might not be a good option because it is very susceptible to scratches and dirt being unstable hence it needs to consider $\mathrm{Rz}$ and contact angle. Along with the physical and mechanical properties of the workpiece even the tool and the grit of sanding disc have a marked effect on the surface quality as they are dependent more on the volumetric ratio of fibres than that of the polymeric matrix. Decreasing the grit size of the sandpaper, surface appears to be flatter but, the high roughness value could be due to increased width and height between irregularities. As shown earlier in microscopic images for type 2, sanding induced moderate damages when the grit size is considerably large. This is consistent with the results of surface roughness. Surface shearing and scratch marks are seen from the machined surfaces. The scratch marks reduced significantly using the finer grit sizes.
The surface with lowest sanding grit had the lowest contact angle. The values of the contact angle are noted for different sanding grit size over a period of 60 s. The contact angle of water droplet increased significantly

over a period. Wettability is defined by both contact angle and surface energy. The higher the surface energy and smaller the contact angle, it leads to more wettability; strong adhesion between two surfaces. Sanding with P80 grit had a contact angle of $36.1^{\circ}$ degree after $35 \mathrm{~s}$ while the finer grit of $\mathrm{P} 400$ showed a contact angle of $63.1^{\circ}$ degree as shown in Figure 22. This trend shows that surface roughness increases wettability of the surface. Generally, sanding or roughening the surface introduces new excited sites along with increasing the interfacial area. A low contact angle is very important to the adhesive flow on the adherend surface to achieve strong bonding. Therefore, it becomes critical to analyse contact angle as a function of surface quality. However, this doesn't mean that a surface with high roughness is suitable for bonding. Although, the contact angle trend justified the need of sanding, the higher and one of the major influence on the surface is during machining.

\subsubsection{Wettability}

\subsection{Overall evaluation}

8

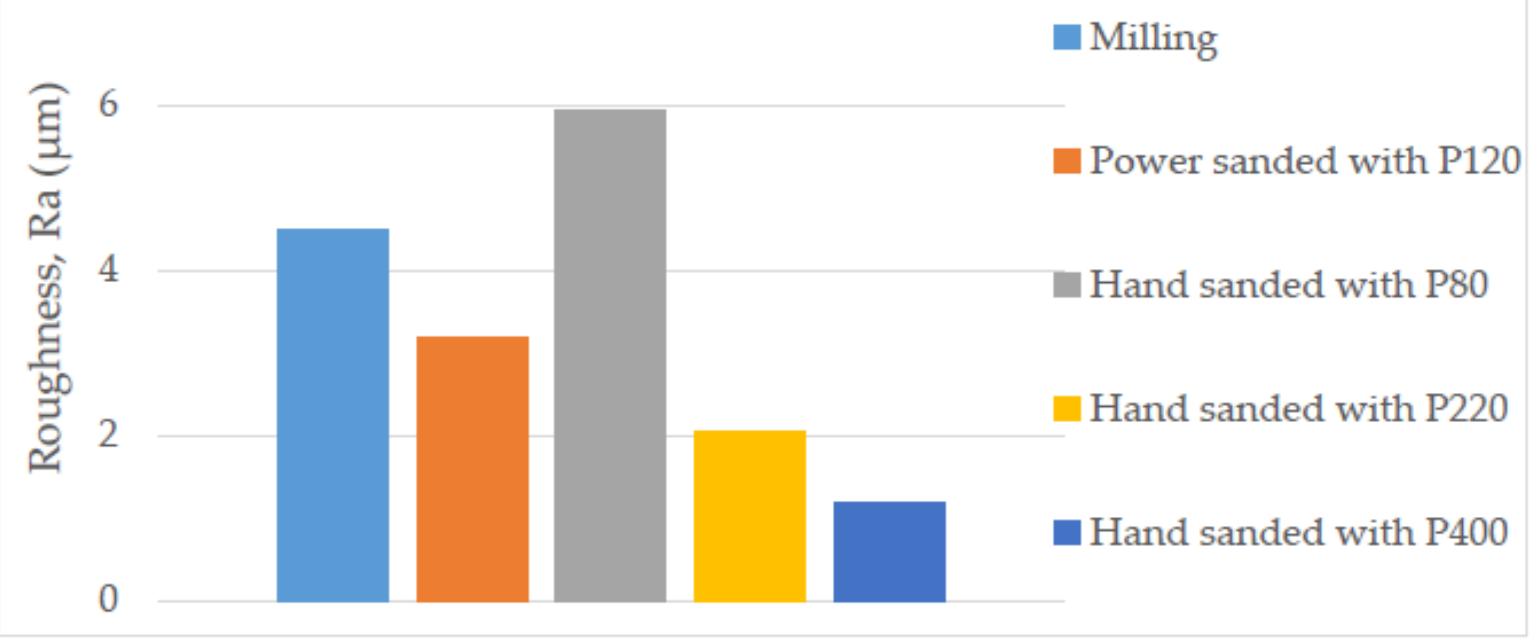

Figure 20: Roughness (Ra) for all the coupon tests 


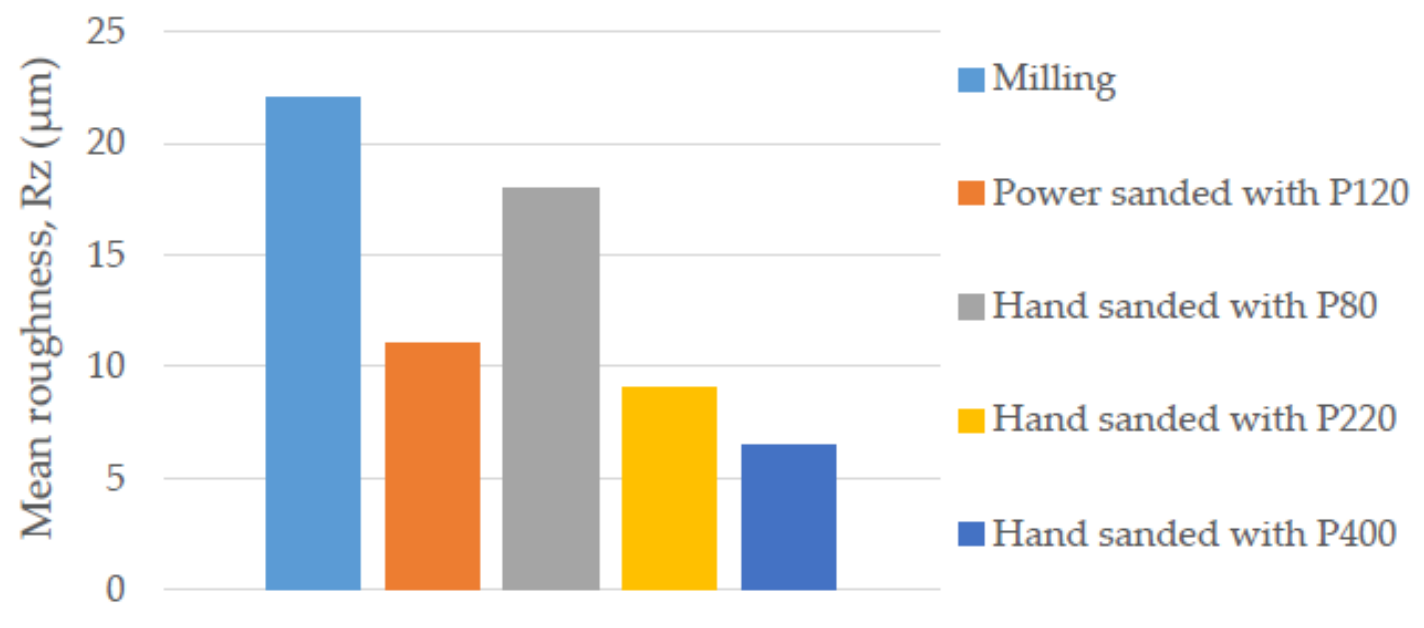

Figure 21: Arithmetic mean roughness (Rz) for all the coupon tests

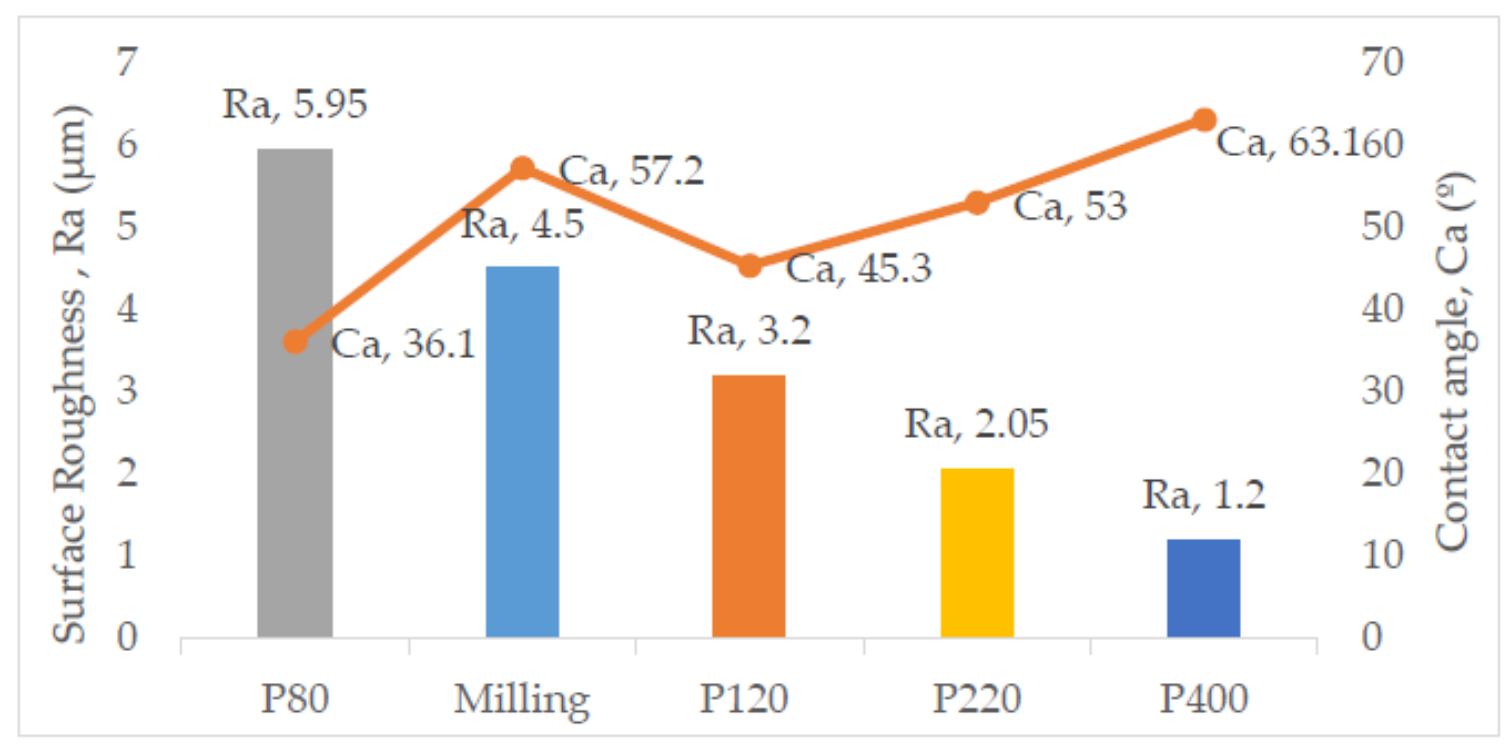

Figure 22: Correlation of surface roughness with contact angle

Figures 20 and 21, compares the values of $\mathrm{Ra}$ and $\mathrm{Rz}$ for all the coupon tests respectively. From the histogram of $\mathrm{Ra}$ values, it can be clearly seen that the sample hand sanded with P80 has the maximum surface roughness and that of P400 has the minimum. In case of P220 the initial operation was done using a power sander (P120) and further hand sanded with P220 this reduces the value of $\mathrm{Ra}$ from $3.2 \mu \mathrm{m}$ to $2.05 \mu \mathrm{m}$ as shown in Figure 20. For milling the roughness is acceptable considering to the use of tool unlike sanding disc and a uniform surface was obtained predicting good bonding characteristics.
Looking at the corresponding $\mathrm{Rz}$ in Figure 21, it is seen that milling has the highest number of peaks and valleys exceeding P80 which can be attributed to its tool geometry and sharp edges of the double cut tool. For P220 the Rz values are notably smaller with $\mathrm{P} 400$ being the least. In addition to $\mathrm{Ra}$ and $\mathrm{Rz}$ the contact angle is one essential factor to be considered when evaluating surface quality. Low contact angle and high surface energy activates the adherend surface for the incoming repair patch to bond effectively with the parent material. In Figure 22, it can be clearly seen how sanding improves the contact angle compared to milling and P120 grit. 
The overall evaluation here shows the correlation of $\mathrm{Ra}, \mathrm{Rz}$ and contact angle to predict the bond quality.

\section{Conclusions}

Experimental results confirm that when $\mathrm{Ra}$ is in the range of 2 to $4 \mu \mathrm{m}$ for $3 \mathrm{~K}$ woven prepreg, the surface quality is better with no or fewer machining defects which is confirmed by microscopic analysis and validated with contact angle i.e. below $60^{\circ}$. The surface roughness of 2-4 $\mu \mathrm{m}$ will ensure uniform distribution of adhesive over the adherend providing adequate mechanical interlocking leading to reliable bonds. High surface roughness in type 2 (P 80) will lead to ridges on the surface and low surface roughness in type 2 (P 400) will not allow proper adhesion. Surface roughness $\mathrm{Ra}$, mean

\section{References}

1. Boeing Ltd. Boeing 737-800 Structural Repair Manual. USA: Boeing Ltd. 2003.

2. Airbus Ltd. Airbus A320 Structural Repair Manual. France: Airbus Ltd. 2007

3. Jones J.S. and Graves S.R., Repair Techniques for Celion-LARC-160 Graphite-Polyimide Composite Structures. NAS1-16448, NASA Langley Research Center, June 1984.

4. Wang C.H. and Gunnion A.J., Composite Science and Technology, 68 (2008) 35-46.

5. Lin G.W., Chen P.H., Acta Aeronautica Et Astronautica Sinica, 30(10) (2009) 1877-1882.

6. Harman A.B., Wang C.H., Damage tolerance and impact resistance of composite scarf joints. ICCM16, 2007, Japan.

7. Cheuk P.T., Tong L., Wang C.H., Baker A., Chalkley P., Fatigue crack growth in adhesively bonded composite-metal double-lap joints, Composite Structures, 2002, pp 109-115.

8. Maxwell J. D., and Andrew M. Assessing adhesive bond failures: Mixed-mode bond failures explained. Adhesion associates. 2010.

9. Kinlock, A.J., Adhesion and Adhesives, Springer Netherlands, 1987, New York. roughness $R z$ and wettability serves as the initial parameters to check the surface prior to bonding. It can be also confirmed from the contact angle analysis of woven glass fibre prepreg that the coarse grit of abrasive material increases the wettability of the surface. Along with this the tool path and cutting depth also affect the surface quality. This technique of surface quality evaluation will be an effective solution to reduce cost in terms of aircraft down time, material and manpower, making the complete process more efficient by minimizing the chances of re-repairs.

Acknowledgments: Author would like to thank Composite Cluster Singapore Pte. Ltd. for providing this opportunity and to equip the author with all the necessary materials and tools to carry out the experiments.

10. Hart-Smith, L.J., "Adhesive Bonded Single Lap Joints," Technical report. 1973. NASA CR 112236.

11. K. Palanikumar, Machining technology for composite materials: Principles and practices, 1st ed. Woodhead Publishing. 2011.

12. J Paolo Davim, Machining of composite materials, ISTE Ltd. and John Wiley and sons, Inc. 1st ed. Great Britain and USA. 2010.

13. Azmi, A.l.; Lin, R.J.T.; Bhattacharyya, D., Experimental study of machinability of GFRP composites by end milling. Materials and Manufacturing Processes,2012, 27 (10), pp 1045-1050.

14. N.S. Hui, L.C. Zhang, A study on the grindability of multidirectional carbon fibre-reinforced plastics. Journal of Materials Processing Technology 2003, 140-152-156.

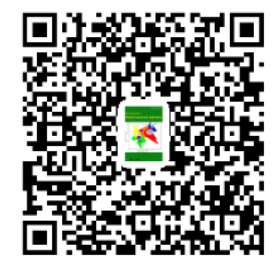

